\title{
Pengaruh Kredibilitas dan Karakteristik Opinion Leader terhadap Behavioral Intention Konsumen pada Media Sosial Instagram
}

\author{
Sri Hartini \\ Arbhie Nugraha Hanafi \\ Manajemen, Universitas Airlangga, Indonesia \\ Korespondensi penulis: arbhienhanafi@gmail.com
}

\begin{abstract}
This study aims to determine the effect of the information source's credibility and characteristic towards opinion leadership, and the effect of opinion leadership on consumer behavioral intention in social media Instagram. The population in this study were all social media users who use Instagram as their fashion reference. The total sample used in this study was 168 people. The sampling method used in this research is purposive sampling. The result obtained from this study indicates that credibility and characteristic have a significant and positive effect on opinion leadership, and opinion leadership has a significant and positive effect on the intention to interact and intention to follow the advice.
\end{abstract}

Keywords: Behavioral intention; Instagram; Opinion leadership; Source credibility; Source characteristic.

\begin{abstract}
Abstrak. Penelitian ini bertujuan untuk mengetahui pengaruh kredibilitas dan karakteristik sumber informasi terhadap opinion leadership dan dampak opinion leadership terhadap behavioral intention konsumen pada media sosial Instagram. Populasi dalam penelitian ini adalah seluruh pengguna media sosial yang menggunakan Instagram sebagai referensi untuk produk fashion yang mereka gunakan. Jumlah sampel yang digunakan dalam penelitian ini sebanyak 168 orang. Teknik pengambilan sampel dalam penelitian ini adalah purposive sampling. Hasil yang diperoleh dari penelitian ini menunjukkan bahwa kredibilitas dan karakteristik sumber informasi memiliki pengaruh positif terhadap opinion leadership, sedangkan opinion leadership memiliki pengaruh positif terhadap niat konsumen untuk berinteraksi dan mengikuti saran.
\end{abstract}

Kata kunci: Instagram; Karakteristik sumber; Kredibilitas sumber; Niat berperilaku; Pemimpin opini. 
Article Info:

Received: May 25, $2020 \quad$ Accepted: November 23, 2020

Available online: February 16, 2021

DOI: http://dx.doi.org/10.30588/jmp.v10i2.704

\section{LATAR BELAKANG}

Pada era digital saat ini, setiap kegiatan manusia tidak terlepas dari internet. Pada tahun 2018, jumlah pengguna internet di dunia secara keseluruhan mencapai lebih dari empat milyar pengguna (Kemp, 2018). Hal ini menunjukkan bahwa lebih dari 50\% penduduk di seluruh dunia menggunakan internet. Penggunaan internet di dunia didominasi oleh para pengguna media sosial. Kemp (2018) mencatat bahwa lebih dari tiga milyar manusia merupakan pengguna aktif media sosial. Media sosial telah mengubah cara manusia untuk berkomunikasi, berkolaborasi, dan terhubung dengan orang lain (Hennig-Thurau, Skiera, Rangaswamy, Malthouse, Gensler, Lobschat, \& Friege, 2010). Meningkatnya jumlah pengguna media sosial merefleksikan kebutuhan manusia melakukan interaksi interpersonal dan media sosial telah membawa aktivitas sosial di dunia nyata ke dalam dunia virtual (Chen \& Lin, 2018). Banyak orang menghabiskan sebagian besar waktunya di media sosial sebagai sarana komunikasi, mencari informasi, dan menghibur diri mereka (Kirvesmies, 2018).

Dengan semakin meningkatnya pengguna media sosial, para pemasar menganggap media sosial sebagai alat yang mudah digunakan untuk meraih konsumen, berkomunikasi, dan terlibat dengan mereka yang dapat mengarahkan mereka untuk melakukan pembelian (Kirvesmies, 2018). Para pemasar juga beranggapan bahwa media sosial merupakan salah satu alat paling menjanjikan untuk beriklan secara digital (Brettel, Reich, Gavilanes, \& Flatten, 2015; Lin \& Kim, 2016). Kegiatan promosi dan iklan dalam media sosial telah dibuktikan sebagai tindakan yang efisien (De Vries \& Carlson, 2014). Iklan online dirasakan lebih informatif dan dapat dipercaya dibandingkan dengan iklan tradisional (Tsang, Ho, \& Liang, 2004) dan secara positif berpengaruh terhadap sikap atas merek dan niat membeli (Wood \& Burkhalter, 2014). Fenomena tersebut membuat pemasar menjadikan media sosial sebagai bagian penting dalam strategi pemasaran mereka.

Belakangan ini, penggunaan media sosial telah dikembangkan oleh kelompok selebritas digital, seperti blogger dan insta-celebrities (Chalal \& Mindi, 2016). Berbeda dengan selebritas tradisional, selebritas digital adalah individu yang menjadi terkenal secara online melalui aktifitas blogging, vlogging, maupun media sosial (Hwang \& Zhang, 2018). Selebritas digital telah diakui sebagai individu yang memiliki pengaruh terhadap pengikut mereka yang banyak (Jin \& Phua, 2014). Selanjutnya, Smith, Coyle, Lightfoot, dan Scott (2007) menjelaskan bahwa selebritas digital dapat menjadi opinion leader dan hal yang mereka bagikan dapat memberikan dampak terhadap merek maupun produk dan dapat mempengaruhi perilaku konsumen.

Casaló, Flavián, dan Ibáñez-Sánchez (2018) dalam penelitiannya, mereka menjelaskan bahwa seseorang di media sosial dianggap sebagai opinion leader, ketika ia memiliki karakteristik yang dibutuhkan menjadi opinion leader antara lain originalitas dan keunikan sebagai sumber informasi. Seorang opinion leader memiliki nilai yang tinggi dalam ino- 
vasi, sehingga opinion leader cenderung mencari hal baru dan tidak biasa (Thakur, Angriawan, \& Summey, 2015). Untuk memilih sosok opinion leader yang dapat digunakan bagi kepentingan pemasaran produk, pemasar perlu mempertimbangkan beberapa hal, salah satunya adalah kredibilitas akun Instagramnya. Clow dan Baack (2018) menyatakan bahwa kredibilitas sumber informasi merupakan faktor penting yang dapat mempengaruhi apakah pesan yang disampaikan dapat dipercaya atau tidak.

Menurut Park (2013), seorang opinion leader dapat memberikan pengaruh terhadap niat konsumen berperilaku. Dalam penelitiannya, Casaló et al. (2018) membagi niat berperilaku konsumen yang ada pada Instagram menjadi tiga macam, yaitu niat untuk berinteraksi, niat untuk merekomendasi, dan niat untuk mengikuti saran dari opinion leaders. Pada konteks media sosial, Casaló et al. (2017) menemukan bahwa orang-orang akan cenderung lebih termotivasi untuk berinteraksi dan merekomendasikan seorang opinion leaders kepada orang lain yang memiliki kebutuhan maupun kepentingan yang sama dengan mereka. Selanjutnya, Rahman, Ali, Saleem, Khan, dan Akhtar (2014) menyatakan bahwa opinion leader dianggap sebagai orang yang memiliki keahlian dan pengetahuan yang lebih dalam atas suatu hal tertentu. Sebagai konsekuensinya, mereka dianggap sebagai ahli atau pakar dan orang-orang akan cenderung mengikuti apa yang dikatakan atau dilakukan oleh opinion leader karena keahliannya tersebut.

Banyak pemasar dan pelaku bisnis yang semakin tertarik untuk menemukan cara memanfaatkan figur terkenal (opinion leader) sebagai duta mereka di media sosial. Sebagaimana laporan Business Insider yang menyatakan bahwa menjalin hubungan dengan opinion leader di media sosial merupakan tindakan penting untuk dilakukan pemasar (Gallagher, 2019). Baik Blog, Youtube, Instagram, maupun Facebook sering menunjukkan produk yang disertai opini para pegiat media sosial atau pun cara mereka mempromosikan produk secara online kepada pengguna lain (Hwang \& Zhang, 2018). Opinion leader dapat muncul di berbagai sektor, seperti kesehatan dan kebugaran, fashion dan kecantikan, teknologi, dan sektor lainnya (Raggatt, Wright, Carrotte, Jenkinson, Mulgrew, Prichard, \& Lim, 2018).

Fashion merupakan salah satu industri penting di dunia bisnis, karena memiliki andil besar dalam perekonomian dunia (Casaló et al., 2018). Semua orang membutuhkan sarana untuk berpenampilan menarik, sedangkan sarana tersebut adalah pakaian untuk memenuhi kebutuhan masyarakat. Kim, Lloyd, dan Cervellon (2016) menyatakan bahwa seseorang akan menggunakan pakaian yang fashionable dan stylish untuk menunjukkan status mereka. Berkatian dengan media sosial, Aragoncillo dan Orus (2018) menyatakan bahwa pengguna media sosial seringkali menggunakan konten yang dibagikan di media sosial sebagai sumber inspirasi untuk berpenampilan. Konsumen bermedia sosial dengan tujuan untuk bertukar informasi dan membicarakan tren fashion yang berkembang (Goldsmith \& Clark, 2008). Wiedmann, Hennigs, dan Langner (2010) menyatakan bahwa social influencer memiliki peranan penting dalam industri fashion.

Casaló et al. (2018) menemukan anteseden dan dampak dari opinion leadership dalam konteks Instagram. Dalam penelitiannya, Casalo et al. (2018) hanya mengungkapkan variabel karakteristik sumber informasi sebagai anteseden opinion leaderhip. Mereka pun menjelaskan bahwa salah satu keterbatasan dalam penelitian tersebut adalah perlunya 
penelitian lebih lanjut dengan menggunakan variabel anteseden yang lebih luas untuk mendapatkan pemahaman lebih komprehensif. Berdasarkan hal itu, penelitian ini memperluas penelitian Casaló et al. (2018) dengan menambahkan variabel anteseden lain, yaitu kredibilitas sumber informasi. Menurut Zhao, Kou, Peng, dan Chen (2018), kredibilitas merupakan faktor krusial yang dapat mempengaruhi persepsi konsumen terhadap seseorang yang memiliki kemampuan opinion leadership. Dengan demikian, penelitian ini bertujuan untuk membuktikan apakah variabel kredibilitas sumber informasi mampu mempengaruhi opinion leadership, yang pada gilirannya juga berdampak terhadap behavioral intention konsumen pada media sosial Instagram.

\section{KAJIAN TEORITIS}

\section{Opinion Leadership}

Seseorang yang tidak memiliki pengalaman dan pengetahuan terhadap suatu hal tertentu cenderung akan mengikuti pendapat atau saran dari orang lain yang dianggap ahli tentang hal tersebut. Orang yang dianggap lebih ahli tentang sesuatu dapat memberikan sugesti yang dapat mempengaruhi keputusan konsumen, karena konsumen merasa percaya dengan orang tersebut (Leal, Hor-Meyll, \& Pessôa, 2014). Seseorang yang dianggap ahli dan dijadikan panutan dalam pengambilan keputusan disebut memiliki kemampuan opinion leadership. Rogers dan Cartano (1962) mendefinisikan opinion leader sebagai individu yang menjadi tempat bagi orang lain untuk mencari saran dan informasi. Seseorang yang memiliki pengaruh terhadap keputusan orang lain dianggap sebagai seorang opinion leader.

Sebelum membuat keputusan, individu seringkali mencari informasi untuk menguatkan keputusan mereka melalui "consensual validation" yang dapat diperoleh melalui opinion leader (Rogers \& Cartano, 1962). Opinion leadership dianggap sebagai kemampuan yang mendapat pengakuan dari publik (McCracken, 1989). Menurut Leal et al. (2014), seseorang dianggap memiliki kemampuan opinion leadership karena memiliki karakteristik, antara lain memiliki keahlian tertentu, memiliki selera yang tinggi, serta memiliki tingkat partisipasi dan kontribusi dalam sebuah komunitas. Selain itu, Park (2013) menyatakan bahwa individu yang memiliki kemampuan opinion leadership merupakan orang yang memiliki status sosial lebih tinggi, mudah berteman, dan melakukan kontak sosial lebih banyak dibandingkan orang lain.

\section{Kredibilitas Sumber Informasi}

Kredibilitas sumber informasi merupakan kepercayaan terhadap beberapa informasi dan atau sumbernya (Hovland, 1953 dalam Casaló et al., 2018). Kredibilitas sumber informasi merujuk pada tingkat kepercayaan konsumen terhadap informasi yang diberikan oleh seseorang (Petty \& Cacioppo, 1986 dalam Casaló et al., 2018). Tanggapan konsumen terhadap kredibilitas sumber informasi akan mempengaruhi sikap mereka terhadap informasi yang didapatkannya (Wood \& Burkhalter, 2014). Semakin tinggi tingkat kredibilitas sumber informasi, maka semakin tinggi pula pengaruh opini mereka. Hal itu dikarenakan sumber informasi yang memiliki kredibilitas tinggi akan memiliki peran yang lebih besar untuk menggiring opini orang lain dibandingkan sumber informasi lain yang memiliki kredibiltas lebih rendah. Seseorang yang memiliki opinion leadership dianggap sebagai 
orang yang diakui oleh masyarakat (McCracken, 1989). Thakur et al. (2015) menyatakan bahwa kredibilitas merupakan anteseden opinion leadership. Kredibilitas seseorang dapat diukur melalui expertise, trustworthiness, dan homophily (Ismagilova, Slade, Rana, \& Dwivedi, 2020). Chaiken (1980) dalam Casaló et al. (2018) menyatakan bahwa penerima pesan dapat mempertimbangkan sebuah pesan yang dianggap kredibel ketika informasi tersebut diberikan oleh orang yang dapat dipercaya. Ketika sebuah akun Instagram dianggap ahli dalam suatu hal dan dapat dipercaya, maka kepercayaan tersebut akan membuat pemilik akun dianggap memiliki opinion leadership (Rahman et al., 2014). Dari uraian tersebut, penelitian ini merumuskan hipotesis kesatu (H1) sebagai berikut:

\section{H1: Kredibilitas sumber informasi berpengaruh positif terhadap opinion leadership.}

\section{Karakteristik Sumber Informasi}

Karakteristik akun media sosial dapat menjadi salah satu anteseden online opinion leaderhip. Casaló, Flavián, Guinalíu, \& Ekinci (2015) menyatakan bahwa karakteristik konten yang dipublikasikan di media sosial dapat mempengaruhi persepsi konsumen. Casaló et al. (2018) menjabarkan karakteristik akun media sosial yang menjadi anteseden opinion leadership, antara lain originality, uniqueness, quality, dan quantity. Originality merupakan sebuah perbuatan yang tidak biasa, inovatif, dan baru. Seorang opinion leader adalah individu yang cenderung melakukan hal-hal inovatif dan dianggap sebagai pelopor. Uniqueness merupakan tingkat keunikan seseorang, sehingga ia merasa berbeda dengan orang-orang lain yang ada di sekitarnya (Maslach, Santee, dan Stapp, 1985). Pada umumnya, orang-orang yang unik menggunakan perilakunya untuk menarik perhatian orang lain. Quality merupakan kualitas kontribusi yang diberikan seseorang dan telah dianggap sebagai hal penting dalam membangun sebuah reputasinya dalam komunitas yang dapat menjadikannya sebagai opinion leader (Leal et al., 2014). Dalam kaitannya dengan media sosial, semakin baik kualitas konten yang dibagikan oleh seseorang, maka ia akan dianggap sebagai opinion leader. Selanjutnya, quantity adalah sebarapa banyak atau seberapa sering seseorang melakukan komunikasi di media sosial. Leal et al. (2014) menyatakan bahwa keaktifan berpartisipasi dalam suatu hal dapat menjadikan seseorang menjadi opinion leader. Lebih lanjut, Rahman et al. (2014) menyatakan bahwa untuk membangun reputasi dalam sebuah komunitas, seseorang harus sering berpartisipasi di dalamnya. Dari uraian tersebut, hipotesis kedua (H2) dirumuskan sebagai berikut:

\section{H2: Karakteristik sumber informasi berpengaruh positif terhadap opinion leader- ship.}

\section{Behavioral Intention}

Park (2013) menyatakan bahwa opinion leaders dapat memberikan pengaruh terhadap consumer behavioral intentions. Casaló et al. (2018) membagi niat berperilaku konsumen yang ada di media sosial Instagram menjadi tiga macam, yaitu niat untuk berinteraksi, niat untuk merekomendasi, dan niat untuk mengikuti saran dari opinion leaders. Interaksi merupakan salah satu syarat untuk mengembangkan dan menjaga hubungan sosial 
(Bourdieu, 1986 dalam Casaló et al. 2018). Chaplin (2011) mendefinisikan interaksi sebagai pertalian sosial antarindividu sedemikian rupa, sehingga individu yang bersangkutan saling mempengaruhi satu sama lain.

Thakur et al. (2015) menjelaskan bahwa opinion leader dianggap memiliki pemahaman terhadap hal spesifik yang membuat orang-orang akan lebih termotivasi untuk berinteraksi dengan mereka dan merekomendasikan orang lain untuk mengikuti apa yang mereka pahami atau lakukan. Ketika seseorang dianggap sebagai opinion leader, maka orang lain akan melakukan interaksi, seperti mendapatkan informasi darinya, karena seorang opinion leader dianggap ahli dalam hal tersebut (Rahman et al., 2014). Sebagai konsekuensi karena dianggap ahli dalam suatu hal, maka para pengikut opinion leader dapat merekomendasikan informasi dari opinion leader tersebut kepada orang lain yang memiliki kebutuhan dan ketertarikan yang sama. Niat untuk merekomendasi dalam penelitian ini adalah niat untuk merekomendasikan akun Instagram opinion leaders kepada orang lain. Casaló et al. (2017) menyatakan bahwa alasan seseorang untuk merekomendasikan akun opinion leaders kepada orang lain dikarenakan adanya kesamaan antara pengirim dan penerima pesan terkait dengan kebutuhan, ketertarikan, permasalahan, dan informasi yang diberikan oleh opinion leaders dianggap relevan bagi mereka. Dari uraian tersebut, maka hipotesis ketiga dan keempat (H3a dan H3b) dirumuskan sebagai berikut:

\section{H3a: Opinion leadership memiliki pengaruh positif terhadap niat untuk berinteraksi. \\ H3b: Opinion leadership memiliki pengaruh positif terhadap niat untuk merekomen- dasikan.}

Penelitian sebelumnya telah menyatakan pengaruh opinion leadership terhadap niat seseorang untuk mengikuti saran yang diberikan oleh opinion leader (Thakur et al., 2015; Casaló et al. 2018). Niat untuk mengikuti saran adalah keinginan seseorang untuk mengikuti saran atau tindakan yang dilakukan oleh orang lain (Casaló et al., 2018). Lebih lanjut, Casaló et al. (2018) menyatakan bahwa seseorang dapat mengikuti saran dari orang lain, karena orang tersebut dianggap ahli dalam hal tertentu atau orang tersebut dapat dipercaya. Berkaitan dengan industri fashion, Rahman et al. (2014) menemukan bahwa opinion leadership memberikan pengaruh terhadap niat beli konsumen untuk membeli baju model terbaru. Hal tersebut terjadi, karena opinion leader cenderung lebih dulu membeli pakaian dengan model terbaru daripada orang lain. Dengan tindakan membelinya itu, mereka dianggap dapat memberikan saran kepada konsumen lain untuk mengikuti jejaknya tersebut. Djafarova dan Rushworth (2017) menjelaskan bahwa konsumen lebih percaya diri untuk membeli sebuah produk apabila telah dirokemendasikan oleh seorang selebritas tertentu. Dari uraian tersebut, hipotesis kelima (H4) dirumuskan sebagai berikut:

\section{H4: Opinion leadership memiliki pengaruh positif terhadap niat untuk mengikuti saran.}




\section{Kerangka Pemikiran}

Individu dianggap sebagai opinion leader, ketika ia memiliki kredibilitas dan karakteristik sebagai sumber informasi. Karena dianggap sebagai ahli atas sesuatu hal yang spesifik, seorang opinion leader dapat memberikan pengaruh terhadap niat konsumen untuk berperilaku, berinteraksi, dan mengikuti saran. Penelitian ini menguji hubungan antarvariabel yang ditunjukkan melalui model penelitian di Gambar 1.

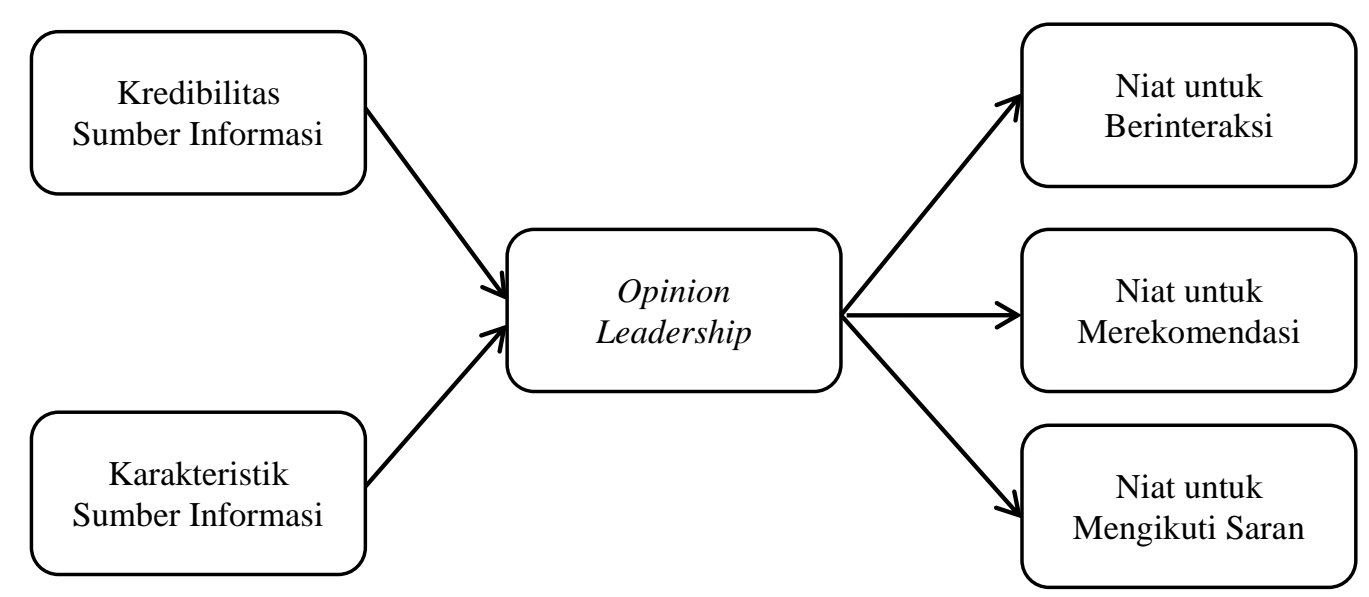

Gambar 1. Model Penelitian

\section{METODE PENELITIAN}

\section{Desain Penelitian}

Jenis penelitian ini adalah penelitian kuantitatif yang bersifat hipotetis, karena penelitian ini bertujuan untuk melakukan pengujian terhadap hipotesis yang mengambarkan hubungan variabel-variabel yang diteliti. Penelitian ini dilakukan selama bulan Mei-Juli 2020 menggunakan instrumen kuesioner melalui media online untuk mengumpulkan data primer dari responden.

\section{Populasi Dan Sampel Penelitian}

Populasi merupakan keseluruhan subyek penelitian dengan karakteristik tertentu yang digunakan dalam penelitian untuk dipelajari (Sugiyono, 2010). Teknik pengambilan sampel dalam penelitian ini mengunakan metode purposive sampling. Sugiyono (2010) menyebutkan bahwa purposive sampling merupakan teknik penentuan sampel penelitian dengan beberapa pertimbangan tertentu yang bertujuan agar data yang diperoleh lebih representatif. Berdasarkan tujuan dan rumusan permasalahan, maka populasi dalam penelitian ini adalah seluruh pengguna media sosial yang menggunakan Instagram sebagai referensi untuk fashion yang mereka gunakan. Dalam penelitian ini, karakteristik sampel yang digunakan, antara lain memiliki dan menggunakan media sosial Instagram, mengikuti akun yang mereka anggap sebagai opinion leader, dan menggunakan Instagram sebagai referensi fashion mereka. 


\section{Tabel 1. Variabel Penelitian}

\begin{tabular}{|c|c|c|}
\hline Variabel & Definisi Operasional & Indikator/Referensi \\
\hline $\begin{array}{l}\text { Kredibilitas } \\
\text { sumber informasi }\end{array}$ & $\begin{array}{l}\text { Kredibilitas nerupakan tingkat kredibilitas akun } \\
\text { media sosial seorang opinion leader sebagai } \\
\text { sumber informasi menurut pengikutnya. }\end{array}$ & $\begin{array}{l}\text { - Keahlian } \\
\text { - Kepercayaan } \\
\text { - Kesamaan } \\
\text { Ismagilova et al. (2020) }\end{array}$ \\
\hline $\begin{array}{l}\text { Karakteristik } \\
\text { sumber informasi }\end{array}$ & $\begin{array}{l}\text { Karakteristik sumber informasi merupakan } \\
\text { karakter konten yang dimiliki seorang opinion } \\
\text { leaders sebagai sumber informasi menurut } \\
\text { pengikutnya. }\end{array}$ & $\begin{array}{l}\text { - Orisinalitas yang } \\
\text { dirasakan } \\
\text { - Keunikan yang dirasakan } \\
\text { Casaló et al. (2018) }\end{array}$ \\
\hline Opinion leadership & $\begin{array}{l}\text { Seberapa besar tingkat seseorang dianggap } \\
\text { sebagai contoh atau panutan bagi orang lain. }\end{array}$ & $\begin{array}{l}\text { - Keandalan } \\
\text { - Sumber informasi } \\
\text { Casaló et al. (2018) }\end{array}$ \\
\hline $\begin{array}{l}\text { Niat untuk } \\
\text { berinteraksi }\end{array}$ & $\begin{array}{l}\text { Niat untuk berinteraksi adalah niat/keinginan } \\
\text { pengikut untuk melakukan interaksi dengan } \\
\text { opinion leader di media social Instagram. }\end{array}$ & $\begin{array}{l}\text { - Kenyamanan } \\
\text { Casaló et al. (2018) }\end{array}$ \\
\hline $\begin{array}{l}\text { Niat untuk } \\
\text { merekomendasikan }\end{array}$ & $\begin{array}{l}\text { Niat untuk merekomendasi adalah niat/keinginan } \\
\text { pengikut untuk merekomendasikan akun opinion } \\
\text { leader di media sosial Instagram. }\end{array}$ & $\begin{array}{l}\text { - Kenyamanan } \\
\text { - Kepercayaan } \\
\text { Casaló et al. (2018) }\end{array}$ \\
\hline $\begin{array}{l}\text { Niat untuk } \\
\text { mengikuti saran }\end{array}$ & $\begin{array}{l}\text { Niat untuk mengikuti saran adalah niat/keinginan } \\
\text { pengikut untuk mengikuti saran opinion leader di } \\
\text { media sosial Instagram. }\end{array}$ & $\begin{array}{l}\text { - Kenyamanan } \\
\text { - Kepercayaan } \\
\text { Casaló et al. (2018) }\end{array}$ \\
\hline
\end{tabular}

Sumber: Referensi terkait.

\section{Instrumen Pengumpulan Data}

Pengumpulan data primer dalam penelitian ini menggunakan instrumen berupa kuesioner. Penelitian ini mengumpulkan data terkait variabel-variabel penelitian yang diteliti meliputi kredibilitas sumber informasi, karakteristik sumber informasi, opinion leadership, niat untuk berinteraksi, niat untuk merekomendasi, dan niat untuk mengikuti saran. Penelitian ini menggunakan aras interval, yaitu aras pengukuran yang memiliki jarak sama dan selisih yang jelas pada skala (Sugiyono, 2010). Skala pengukuran yang digunakan dalam penelitian ini adalah skala Likert. Definisi operasional untuk setiap variabel penelitian ini beserta indikator dan dasar acuannya ditunjukkan pada Tabel 1. Responden diminta untuk memberikan penilaian terhadap pernyataan-pernyataan yang tercantum di dalam kuesioner. Jawaban responden diukur dengan lima skala jenjang.

\section{Teknik Analisis Data}

Analisis data dalam penelitian ini menggunakan teknik analisis structural equation modeling (SEM) dengan bantuan aplikasi AMOS (Analysis of Moment Structures) versi 22. SEM merupakan teknik statistik multivariat yang mengkombinasikan antara analisis faktor dan analisis regresi (korelasi). Analisis tersebut bertujuan untuk menguji hubungan antarvariabel yang ada pada model penelitian, baik antarindikator dengan konstraknya atau pun hubungan antarkonstrak (Santoso, 2018). SEM lebih tepat digunakan untuk melakukan confirmatory analysis daripada exploratory analysis. Santoso (2018) juga menjelaskan bahwa SEM digunakan untuk menguji model yang dibuat dengan teori tertentu, apakah model tersebut bisa diterima atau ditolak. 


\section{HASIL DAN PEMBAHASAN}

\section{Analisis Profil Responden}

Responden dalam penelitian ini adalah pengguna media sosial Instagram berdasarkan kriteria tertentu yang telah ditetapkan dalam penelitian ini. Responden yang terpilih dalam penelitian ini berjumlah 168 orang sesuai dengan kriteria. Berdasarkan jenis kelamin, responden dalam penelitian ini terdiri atas perempuan sebanyak 119 orang atau 70,8\%, sedangkan laki-laki sebanyak 49 orang atau 29,2\%. Pada umumnya, pengguna Instagram mengikuti akun selebgram dengan maksud untuk mengikuti tren pakaian (fashion) dari para selebgram perempuan. Instagram termasuk salah satu jejaring sosial yangberkembang pesat dan mampu memberikan dampak positif dan negatif terhadap gaya hidup seseorang (Mefita \& Yulianto, 2018). Selebgram dikenal sebagai selebriti Instagram, yaitu para pegiat media sosial Instagram yang memiliki banyak pengikut (followers) yang tertarik terhadap konten kreatifnya (Sakinah, 2018; iBig Academy, 2019), sehingga para selebgram tersebut memiliki pengaruh kuat mengarahkan para pengikutnya untuk menerima atau menolak suatu hal (Mefita \& Yulianto, 2018).

Berdasarkan usia, mayoritas responden dalam penelitian ini berusia 17-24 tahun sebanyak 150 orang atau 89,3\%, sedangkan dengan jumlah terkecil adalah responden yang berusia 25-30 tahun sebanyak 18 orang atau 10,7\%. Secara umum, kondisi ini disebabkan oleh pengguna Instagram yang mengikuti akun selebgram tertentu untuk mengikuti tren fashion adalah pelajar dan mahasiswa. Berdasarkan tingkat pendapatan, mayoritas responden dalam penelitian ini memiliki pendapatn pada kisaran Rp1.000.000-Rp4.999.999 sebanyak 68 orang atau 40,5\%. Gambaran ini menunjukkan bahwa pengguna Instagram yang mengikuti akun selebgram tertentu tersebut berusia pelajar dan mahasiswa yang memperoleh pendapatan dari orang tua mereka dan beberapa dari mereka memiliki pekerjaan sampingan.

\section{Uji Validitas}

Uji validitas adalah pengujian yang dilakukan terhadap indikator variabel-variabel yang diteliti apakah memiliki proporsi varian yang tinggi atau tidak dengan menilai loading factor yang dapat merefleksikan hubungan antara masing- masing butir pernyataan dengan variabel laten. Uji validitas dianggap memenuhi kriteria apabila loading factor $\geq 0,50$ (Santoso, 2018). Hasil uji validitas terhadap instrumen penelitian ini menunjukkan bahwa seluruh butir indikator atas semua variabel penelitian seperti yang ditunjukkan pada Tabel 2 memiliki nilai loading factor $\geq 0,50$, sehingga seluruh butir instrumen penelitian ini dinyatakan valid dan dapat digunakan untuk analisis selanjutnya.

\section{Uji Reliabilitas}

Uji reliabilitas digunakan untuk mengetahui apakah alat pengukur atau instrumen yang digunakan dalam penelitian ini dapat diandalkan dan tetap konsisten apabila pengukuran tersebut diulang pada waktu yang berbeda. Uji reliabilitas dilakukan menggunakan uji construct reliability, yaitu menguji keandalan dan konsistensi data. Relibilitas memenuhi kriteria apabila construct reliability > 0,70 (Santoso, 2018). Hasil uji reliabilitas pada instrumen penelitian ini menunjukkan bahwa seluruh variabel penelitian memiliki nilai reliabilitas konstrak lebih besar dari 0,70 seperti yang diperlihatkan pada Tabel 3. Oleh 
karena itu, uji reliabilitas penelitian ini dapat diterima, sehingga seluruh butir instrumen penelitian ini dinyatakan reliabel dan dapat digunakan untuk analisis di masa mendatang.

Tabel 2. Hasil Uji Validitas

\begin{tabular}{|c|c|c|c|c|}
\hline \multicolumn{3}{|c|}{ Butir Pernyataan } & \multirow{2}{*}{$\begin{array}{c}\text { Estimate } \\
0,881\end{array}$} & \multirow{2}{*}{$\begin{array}{c}\text { Keterangan } \\
\text { Valid }\end{array}$} \\
\hline IAC1 & $\longleftarrow$ & Kredibilitas sumber informasi & & \\
\hline IAC2 & $\leftarrow$ & Kredibilitas sumber informasi & 0,795 & Valid \\
\hline IAC3 & $\longleftarrow$ & Kredibilitas sumber informasi & 0,686 & Valid \\
\hline IACR1 & $\leftarrow$ & Karakteristik sumber informasi & 0,786 & Valid \\
\hline IACR2 & $\longleftarrow$ & Karakteristik sumber informasi & 0,888 & Valid \\
\hline IACR3 & $\leftarrow$ & Karakteristik sumber informasi & 0,860 & Valid \\
\hline IACR4 & $\longleftarrow$ & Karakteristik sumber informasi & 0,630 & Valid \\
\hline OL1 & $\longleftarrow$ & Opinion Leadership & 0,770 & Valid \\
\hline OL2 & $\leftarrow$ & Opinion Leadership & 0,789 & Valid \\
\hline OL3 & $\longleftarrow$ & Opinion Leadership & 0,861 & Valid \\
\hline OL4 & $\leftarrow$ & Opinion Leadership & 0,757 & Valid \\
\hline II1 & $\longleftarrow$ & Niat untuk berinteraksi & 0,840 & Valid \\
\hline II2 & $\longleftarrow$ & Niat untuk berinteraksi & 0,804 & Valid \\
\hline II3 & $\leftarrow$ & Niat untuk berinteraksi & 0,944 & Valid \\
\hline IR1 & $\leftarrow$ & Niat untuk merekomendasikan & 0,801 & Valid \\
\hline IR2 & $\leftarrow$ & Niat untuk merekomendasikan & 0,876 & Valid \\
\hline IR3 & $\longleftarrow$ & Niat untuk merekomendasikan & 0,775 & Valid \\
\hline IF1 & $\leftarrow$ & Niat untuk mengikuti saran & 0,636 & Valid \\
\hline IF2 & $\leftarrow$ & Niat untuk mengikuti saran & 0,941 & Valid \\
\hline IF3 & $\longleftarrow$ & Niat untuk mengikuti saran & 0,632 & Valid \\
\hline
\end{tabular}

Keterangan:

IAC=Instagram Account Characteristic; IACR=Instagram Account Credibility; OL=Opinion Leadership; II=Intention to Interact; IR=Intention to Recommend; $\mathrm{IF}=$ Intention to Follow the Advice.

Sumber: Data primer diolah menggunakan AMOS 22 (2020).

\section{Uji Kesesuaian Model}

Pada tahap analisis kesesuaian terhadap full structural model, maka model penelitian ini dilakukan evaluasi menggunakan goodness of fit index. Hasil perhitungan nilai-nilai indeks pada goodness of fit yang dihasilkan oleh model penelitian ini ditunjukkan pada Tabel 4 . Hasil pengujian goodness of fit menunjukkan bahwa model SEM pada penelitian ini sudah baik dan dapat diterima. Dengan demikian, analisis uji hipotesis lebih lanjut dapat dilakukan. 
Tabel 3. Hasil Uji Reliabilitas

\begin{tabular}{lcc}
\hline \multicolumn{1}{c}{ Variabel } & Reliabilitas & Keterangan \\
\hline IAC (kredibilitas sumber informasi) & 0,833 & Reliabel \\
\hline IACR (karakteristik sumber informasi) & 0,873 & Reliabel \\
\hline OL (opinion leadership) & 0,873 & Reliabel \\
\hline II (niat untuk berinteraksi) & 0,898 & Reliabel \\
\hline IR (niat untuk merekomendasikan) & 0,859 & Reliabel \\
\hline IF (niat untuk mengikuti saran) & 0,788 & Reliabel \\
\hline
\end{tabular}

Keterangan:

$\mathrm{IAC}=$ Instagram Account Characteristic; $\mathrm{IACR}=$ Instagram Account Credibility; $\mathrm{OL}=$ Opinion Leadership; II=Intention to Interact; $\mathrm{IR}=$ Intention to Recommend; $\mathrm{IF}=$ Intention to Follow the Advice.

Sumber: Data primer diolah menggunakan AMOS 22 (2020).

Tabel 4. Uji Goodness of Fit

\begin{tabular}{cccc}
\hline Goodness of fit Index & Cut of value & Model & Kriteria \\
\hline CMIN/DF & $\leq 2,0$ & 1,848 & Good Fit \\
CFI & $\geq 9,0$ & 0,920 & Good Fit \\
\hline TLI & $\geq 9,0$ & 0,907 & Good Fit \\
\hline NFI & $\geq 9,0$ & 0,842 & Marginal \\
GFI & $\geq 9,0$ & 0,854 & Marginal \\
\hline AGFI & $\geq 8,0$ & 0,813 & Good Fit \\
\hline RMSEA & $\leq 0,08$ & 0,071 & Good Fit \\
\hline
\end{tabular}

Keterangan:

CMIN/DF=Chi Square/Degree of Freedom; CFI=Comparative Fit Index; TLI=Tucker-Lewis Index; NFI=Normed Fit Index; GFI=Goodness of Fit Index; AGFI=Adjusted Goodness of Fit Index; RMSEA=Root Mean Square Error of Approximation.

Sumber: Data primer diolah menggunakan AMOS 22 (2020).

\section{Pengujian Hipotesis dan Pembahasan}

Berdasarkan hasil uji hipotesis pada model penelitian ini dengan nilai signifikansi 5\% yang ditunjukkan pada Tabel 5, empat hipotesis yang diuji menunjukkan pengaruh signifikan dan satu hipotesis membuktikan pengaruh tidak signifikan. Hasil pengujian hipotesis penelitian ini diuraikan berikut ini.

\section{a. Pengaruh Kredibilitas sumber informasi terhadap Opinion Leadership}

Hasil pengujian hipotesis kesatu (H1) menunjukkan bahwa kredibilitas sumber informasi memberikan pengaruh signifikan terhadap opinion leadership. Dengan demikian, variabel kredibilitas sumber informasi dapat mempengaruhi tingkat kepercayaan konsumen kepada opinion leader. Semakin tinggi kredibilitas orang tersebut, maka semakin kuat opinion leadership yang ia miliki. Hasil penelitian ini sejalan dengan penelitian Thakur et al. (2015) yang menyatakan bahwa kredibilitas sumber merupakan variabel penting yang menjadikan seseorang dapat dianggap sebagai opinion leader. 
Tabel 5. Uji Hipotesis

\begin{tabular}{|c|c|c|c|c|}
\hline Hipotesis & Variabel & C.R. & Prob. & Keterangan \\
\hline H1 & Opinion Leadership $\leftarrow$ Credibility & 3,721 & 0,000 & Signifikan \\
\hline $\mathrm{H} 2$ & Opinion Leadership $\leftarrow$ Characteristic & 3,051 & 0,000 & Signifikan \\
\hline $\mathrm{H} 3 \mathrm{a}$ & Intention to Interact $\leftarrow$ Opinion Leadership & 4,036 & 0,000 & Signifikan \\
\hline $\mathrm{H} 3 \mathrm{~b}$ & Intention to Recommend & 1,010 & 0,313 & $\begin{array}{c}\text { Tidak } \\
\text { Signifikan }\end{array}$ \\
\hline $\mathrm{H} 3 \mathrm{c}$ & Intention to Follow Advice $\leftarrow$ Opinion Leadership & 2,408 & 0,016 & Signifikan \\
\hline
\end{tabular}

Sumber: Data primer diolah menggunakan AMOS (2020).

\section{b. Pengaruh Karakteristik sumber informasi terhadap Opinion Leader}

Hasil pengujian hipotesis kedua (H2) menunjukkan bahwa karakteristik sumber informasi memberikan pengaruh signifikan terhadap opinion leadership. Dengan demikian, variabel karakteristik sumber informasi dapat mempengaruhi tingkat seseorang, sehingga ia dianggap sebagai opinion leader. Hasil ini sejalan dengan penelitian Casaló et al. (2018) yang menyatakan bahwa karakteristik sumber memiliki pengaruh positif terhadap opinion leadership. Semakin berkarakter seseorang, maka semakin tinggi pula kemungkinannya dianggap sebagai opinion leader.

\section{c. Pengaruh Opinion Leadership terhadap Niat untuk Berinteraksi}

Hasil pengujian hipotesis ketiga (H3a) menunjukkan bahwa opinion leadership memiliki pengaruh signifikan terhadap niat untuk berinteraksi. Semakin tinggi kuat seseorang dianggap sebagai opinion leader, maka semakin tinggi pula keinginan orang lain untuk melakukan interaksi dengannya. Hal ini sejalan dengan penelitian Park (2013) yang menyatakan bahwa opinion leader akan memberikan pengaruh positif terhadap niat berperilaku konsumen. Thakur et al. (2015) menyatakan bahwa hal itu disebabkan karena seorang opinion leader dianggap memiliki pengetahuan terhadap sesuatu hal tertentu yang membuat orang lain tertarik untuk berinteraksi dengannya.

\section{d. Pengaruh Opinion Leadership terhadap Niat untuk Merekomendasikan}

Hasil pengujian hipotesis keempat (H3b) menunjukkan bahwa opinion leadership tidak memiliki pengaruh signifikan terhadap niat untuk merekomendasi. Hal ini berbanding terbalik dengan hasil penelitian sebelumnya oleh Casaló et al. (2018) yang menyatakan bahwa opinion leader memiliki pengaruh terhadap niat untuk merekomendasi. Hal ini dikarenakan bahwa para selebgram yang diikuti oleh responden merupakan selebgram yang sudah banyak dikenal oleh banyak orang lain, sehingga mereka tidak perlu untuk merekomendasikannya kepada orang lain lagi. Kim et al. (2016) dalam penelitiannya menemukan hasil yang sama dengan penelitian ini, yaitu opinion leadership tidak memiliki pengaruh terhadap niat untuk merekomendasikan, karena seorang opinion leader dianggap telah memiliki tingkat popularitas yang tinggi dan memiliki pengikut yang banyak. Dengan demikian, hal itu tidak perlu direkomendasikan lagi oleh orang lain. 


\section{e. Pengaruh Opinion Leadership terhadap Niat untuk Mengikuti Saran}

Hasil pengujian hipotesis kelima (H4) menunjukkan bahwa opinion leadership memiliki pengaruh signfikan terhadap niat untuk mengikuti saran. Semakin kuat seseorang dianggap sebagai opinion leader, maka semakin tinggi pula keinginan orang lain untuk mengikuti saran yang ia berikan. Hal ini dikarenakan opinion leader dianggap sebagai ahli dan dapat mempengaruhi orang lain dalam pengambilan keputusan. Hasil penelitian ini ini sejalan dengan Casaló et al. (2018) yang menyatakan bahwa opinion leader memiliki pengaruh terhadap niat untuk mengikuti saran.

\section{KESIMPULAN DAN SARAN}

Berdasarkan hasil pengujian hipotesis dalam penelitian ini, variabel kredibilitas dan karakteristik sumber informasi memiliki pengaruh positif dan signifikan terhadap opinion leadership. Hasil ini mengindikasikan bahwa semakin tinggi tingkat kredibilitas dan karakteristik seseorang, maka anggapan orang lain atau konsumen akan semakin tinggi pula atas kemampuannya memiliki opinion leadership. Penelitian ini juga menemukan bahwa variabel opinion leadership memberikan pengaruh positif dan signifikan terhadap niat untuk berinteraksi dan niat untuk mengikuti saran. Hasil tersebut menunjukkan bahwa seorang opinion leader dapat memberikan pengaruh kepada orang lain yang mengikutinya memiliki niat untuk berinteraksi dengannya dan berniat mengikuti saran yang ia berikan.

Berdasarkan hasil penelitian ini, para pemasar disarankan untuk mempertimbangkan kredibilitas dan karakteristik seseorang yang dianggap sebagai sumber informasi karena memiliki kemampuan opinon leadership. Jika seorang opinion leader semakin kredibel dan berkarakter, maka ia akan dapat meningkatkan niat konsumen untuk berinteraksi dan mengikuti saran yang diberikan.

\section{DAFTAR REFERENSI}

Aragoncillo, L., \& Orus, C. (2018). Impulse Buying Behaviour: An Online-offline Comparative and the Impact of Social Media. Spanish Journal of Marketing - ESIC, 22(1), 42-62. https://doi.org/10.1108/sjme-03-2018-007.

Brettel, M., Reich, J.-C., Gavilanes, J. M., \& Flatten, T. C. (2015). What Drives Advertising Success on Facebook? An Advertising-Effectiveness Model. Journal of Advertising Research, 55(2), 162-175. https://doi.org/10.2501/jar-55-2-162-175.

Casaló, L. V., Flavián, C., Guinalíu, M., \& Ekinci, Y. (2015). Avoiding the Dark Side of Positive Online Consumer Reviews: Enhancing Reviews' Usefulness for High Riskaverse Travelers. Journal of Business Research, 68(9), 1829-1835. https://doi.org/10.1016/j.jbusres.2015.01.010.

Casaló, L. V., Flavián, C., \& Ibáñez-Sánchez, S. (2017). Antecedents of Consumer Intention to Follow and Recommend an Instagram Account. Online Information Review, 41(7), 1046-1063. https://doi.org/https://doi.org/10.1108/OIR-09-2016-0253. 
Casaló, L. V., Flavián, C., \& Ibáñez-Sánchez, S. (2018). Influencers on Instagram: Antecedents and Consequences of Opinion Leadership. Journal of Business Research, 117, 510-519. https://doi.org/10.1016/j.jbusres.2018.07.005.

Chaplin, J. P. (2011). Kamus Lengkap Psikologi. Jakarta: Rajagrafindo Persada.

Chen, S. C., \& Lin, C. P. (2018). Understanding the Effect of Social Media Marketing Activities: The Mediation of Social Identification, Perceived Value, and Satisfaction. Technological Forecasting and Social Change, 140(December 2018), 22-32. https://doi.org/10.1016/j.techfore.2018.11.025.

Clow, K. E., \& Baack, D. (2018). Integrated Advertising, Promotion, and Marketing Communications. $8^{\text {th }}$ Edition. New York: Pearson, Inc.

De Vries, N. J., \& Carlson, J. (2014). Examining the Drivers and Brand Performance Implications of Customer Engagement with Brands in the Social Media Environment. Journal of Brand Management, 21(6), 495-515. https://doi.org/10.1057/bm.2014.18.

Djafarova, E., \& Rushworth, C. (2017). Exploring the Credibility of Online Celebrities' Instagram Profiles in Influencing the Purchase Decisions of Young Female Users. Computers in Human Behavior, 68, 1-7.

Gallagher, K. (2019). The Influencer Marketing Report: Research, Strategy \& Platforms for Leveraging Social Media Influencers. Diakses tanggal 10 Mei 2020 pada https://www.businessinsider.in/the-influencer-marketing-report-research-strategyplatforms-for-leveraging-social-media-influencers/articleshow/70123958.cms.

Goldsmith, R. E., \& Clark, R. A. (2008). An Analysis of Factors Affecting Fashion Opinion Leadership and Fashion Opinion Seeking. Journal of Fashion Marketing and Management: An International Journal, 12(3), 308-322. https://doi.org/10.1108/13612020810889272.

Hennig-Thurau, T., Skiera, B., Rangaswamy, A., Malthouse, E. C., Gensler, S., Lobschat, L., \& Friege, C. (2010). The Impact of New Media on Customer Relationships. Journal of Service Research, 13(3), 311-330. https://doi.org/10.1177/1094670510375460.

Hwang, K., \& Zhang, Q. (2018). Influence of Parasocial Relationship between Digital Celebrities and their Followers on Followers' Purchase and Electronic Word-ofmouth Intentions, and Persuasion Knowledge. Computers in Human Behavior, 87(May), 155-173. https://doi.org/10.1016/j.chb.2018.05.029.

iBig Academy (2019). Apa itu Selebgram? Ini Dia Asal Usulnya. Diakses tanggal 18 November 2020 pada https://www.ibigacademy.com/apa-itu-selebgram-asal-usulendorse.

Ismagilova, E., Slade, E., Rana, N. P., \& Dwivedi, Y. K. (2020). The Effect of Characteristics of Source Credibility on Consumer Behaviour: A Meta-analysis. Journal of Retailing and Consumer Services, 53, 1203-1226. https://doi.org/10.1016/j.jretconser.2019.01.005.

Jin, S. A. A., \& Phua, J. (2014). Following Celebrities' Tweets about Brands: The Impact of Twitter-based Electronic Word-of-mouth on Consumers Source Credibility Perception, Buying Intention, and Social Identification with Celebrities. Journal of Advertising, 43(2), 181-195. https://doi.org/10.1080/00913367.2013.827606. 
Kemp, S. (2018). Digital in 2018: World's Internet Users Pass the 4 Billion Mark. Diakses tanggal 16 Mei 2020 pada https://wearesocial.com/blog/2018/01/global-digitalreport-2018.

Kim, J. E., Lloyd, S., \& Cervellon, M. C. (2016). Narrative-transportation Storylines in Luxury Brand Advertising: Motivating Consumer Engagement. Journal of Business Research, 69(1), 304-313. https://doi.org/10.1016/j.jbusres.2015.08.002.

Kirvesmies, T. (2018). Parasocial Relationships between Gen Z and Social Media Endorsers. University of Tampere.

Leal, G. P. A., Hor-Meyll, L. F., \& Pessôa, L. A. G. de P. (2014). Influence of Virtual Communities in Purchasing Decisions: The Participants' Perspective. Journal of Business Research, 67(5), 882-890. https://doi.org/10.1016/j.jbusres.2013.07.007.

Lin, C. A., \& Kim, T. (2016). Predicting User Response to Sponsored Advertising on Social Media via the Technology Acceptance Model. Computers in Human Behavior, 64, 710-718. https://doi.org/10.1016/j.chb.2016.07.027.

Maslach, C., Santee, R. T., \& Stapp, J. (1985). Individuation: Conceptual Analysis and Assessment. Journal of Personality and Social Psychology, 49(3), 729-738.

McCracken, G. (1989). Who Is the Celebrity Endorser? Cultural Foundations of the Endorsement Process. Journal of Consumer Research, 16(December), 310-321.

Mefita, S., \& Yulianto, M. (2018). Fenomena Gaya Hidup Selebgram (Studi Fenomenologi Selebgram Awkarin). Interaksi Online, 6(4), 567-573.

Park, C. S. (2013). Does Twitter Motivate Involvement in Politics? Tweeting, Opinion Leadership, and Political Engagement. Computers in Human Behavior, 29(4), 16411648. https://doi.org/10.1016/j.chb.2013.01.044.

Raggatt, M., Wright, C. J. C., Carrotte, E., Jenkinson, R., Mulgrew, K., Prichard, I., \& Lim, M. S. C. (2018). "I aspire to look and feel healthy like the posts convey": Engagement with Fitness Inspiration on Social Media and Perceptions of Its Influence on Health and Wellbeing. BMC Public Health, 18, 1-11. https://doi.org/10.1186/s12889-018-5930-7.

Rahman, S. U., Ali, T., Saleem, S., Khan, M. A., \& Akhtar, S. (2014). Consumers' Adoption of Apparel Fashion: The Role of Innovativeness, Involvement, and Social Values. International Journal of Marketing Studies, 6(3), 49-64. https://doi.org/10.5539/ijms.v6n3p49.

Rogers, E. M., \& Cartano, D. G. (1962). Methods of Measuring Opinion Leadership. Public Opinion Quarterly, 26(3), 435-441.

Sakinah, S. (2018). Selebgram: Meraih Popularitas melalui Dunia Maya. Etnosia: Jurnal Etnografi Indonesia, 3(1), 48-71.

Santoso, S. (2018). Menguasai Statistik dengan SPSS 25. Jakarta: PT Elex Media Komputindo.

Smith, T., Coyle, J. R., Lightfoot, E., \& Scott, A. (2007). Reconsidering Models of Influence: The Relationship between Consumer Social Networks and Word-of-Mouth Effectiveness. Journal of Advertising Research, 47(4), 387-397. https://doi.org/10.2501/s0021849907070407. 
Sugiyono, S. (2010). Metode Penelitian Pendidikan Pendekatan Kuantitatif, Kualitatif, dan $R \& D$. Bandung: Alfabeta.

Thakur, R., Angriawan, A., \& Summey, J. H. (2015). Technological Opinion Leadership: The Role of Personal Innovativeness, Gadget Love, and Technological Innovativeness. Journal of Business Research, 69, 2764-2773. https://doi.org/10.1016/j.jbusres.2015.11.012.

Tsang, M. M., Ho, S., \& Liang, T. (2004). Consumer Attitudes Toward Mobile Advertising: An Empirical Study Consumer Attitudes toward Mobile Advertising. International Journal of Electronic Commerce, 8(3), 65-78. https://doi.org/10.1080/10864415.2004.11044301.

Wiedmann, K. P., Hennigs, N., \& Langner, S. (2010). Spreading the word of fashion: Identifying social influencers in fashion marketing. Journal of Global Fashion Marketing, 1(3), 142-153. https://doi.org/10.1080/20932685.2010.10593066

Wood, N. T., \& Burkhalter, J. N. (2014). Tweet This, Not That: A Comparison between Brand Promotions in Microblogging Environments Using Celebrity and Companygenerated Tweets. Journal of Marketing Communications, 20(1-2), 129-146. https://doi.org/10.1080/13527266.2013.797784.

Zhao, Y., Kou, G., Peng, Y., \& Chen, Y. (2018). Understanding Influence Power of Opinion Leaders in E-commerce Networks: An Opinion Dynamics Theory Perspective. Information Sciences, 426, 131-147. https://doi.org/10.1016/j.ins.2017.10.031. 